This item was submitted to Loughborough's Research Repository by the author.

Items in Figshare are protected by copyright, with all rights reserved, unless otherwise indicated.

\title{
Construction tools and equipment - their influence on accident causality
}

PLEASE CITE THE PUBLISHED VERSION

PUBLISHER

(C) Emerald

VERSION

AM (Accepted Manuscript)

LICENCE

CC BY-NC-ND 4.0

\section{REPOSITORY RECORD}

Gibb, Alistair G.F., Sophie Hide, Roger Haslam, Diane E. Gyi, Trevor C. Pavitt, Sarah Atkinson, and Roy Duff. 2019. "Construction Tools and Equipment - Their Influence on Accident Causality". figshare. https://hdl.handle.net/2134/5940. 
This item was submitted to Loughborough's Institutional Repository (https://dspace.lboro.ac.uk/) by the author and is made available under the following Creative Commons Licence conditions.

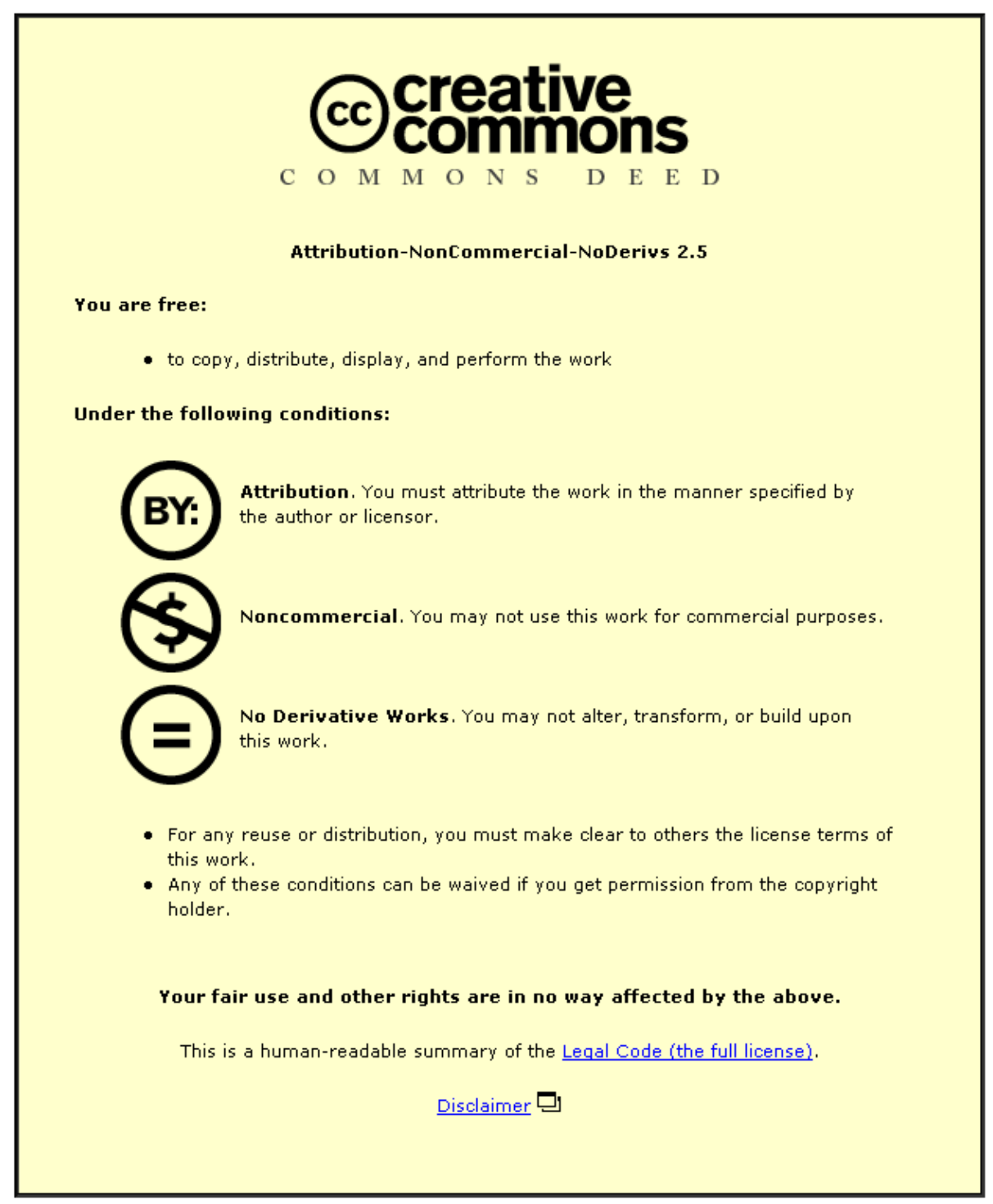

For the full text of this licence, please go to: http://creativecommons.org/licenses/by-nc-nd/2.5/ 


\title{
Construction tools and equipment - their influence on accident causality
}

\author{
Alistair Gibb; Sophie Hide; Roger Haslam; Diane Gyi; Trevor Pavitt; Sarah \\ Atkinson \\ APaCHe (Partnership for Construction Health and Safety), Loughborough University, \\ UK
}

\section{Roy Duff}

UMIST Manchester, UK.

Gibb, A.G.F., Hide, S., Haslam, R.A., Gyi, D.E., Atkinson, S. \& Duff, R, Construction tools and equipment - their influence on accident causality, Journal of Engineering Design \& Technology (JEDT), 2005, Volume 3 Issue 1 pp. 12-23, ISSN 1726-0531

\begin{abstract}
This paper presents tools and equipment aspects of the results from a three-year United Kingdom Government-funded research project investigating accident causality (ConCA). The project has used focus groups and studied in detail 100 construction accidents site audits, interviews with involved persons and follow-up along the causal chain. This paper concentrates on the influence of construction tools and equipment which were found to be important contributory factors identified by the research. They have largely been overlooked by previous studies and are not typically acknowledged as accident contributors. This paper argues for further work to confirm these links and for the inclusion of tools and equipment in the list of categories in statutory reporting procedures. This would also require an increased acknowledgement by construction managers of their influence, leading to better design and management of their supply and care on site.
\end{abstract}

Key Words

construction accident causality; tools; equipment; PPE 


\title{
Construction tools and equipment - their influence on accident causality
}

\author{
Alistair Gibb; Sophie Hide; Roger Haslam; Diane Gyi; Trevor Pavitt; Sarah \\ Atkinson \\ APaCHe, Loughborough University, UK \\ Roy Duff \\ UMIST Manchester, UK
}

\section{Introduction and Method}

Are accidents really accidental or are they 'caused' by something? Most experts concur with the latter view, although there are differing opinions regarding the nature of causes and their relationship (Whittington et al, 1992; Hinze, 1996; Abdelhamid and Everett, 2000; Suraji et al, 2000). A full discussion of these approaches is outside the scope of this paper, however, there is no doubt that the most appropriate approach is to accept multiple causality (Reason, 1990). This paper argues that tools and equipment should be included in these multi-causal influences although they are often missed in accident reporting regimes.

This paper presents findings relating to tools and equipment from ConCA - a threeyear project studying accident causality in construction and funded by the United Kingdom (UK) Health and Safety Executive (HSE), the Government body responsible for health and safety. The full report has been published by the HSE (Haslam et al, 2003), identifying a number of causal factors under the following headings:

- Worker factors

- Site factors

- Materials, tools and equipment factors

- Underlying causes

This paper concentrates on tools and equipment aspects. Interested readers should view the full report for a complete coverage of method and results. Other aspects of this work have also been published elsewhere (Haslam et al, 2005; Hide et al, 2000, 2001, 2002, 2003).

The ConCA project emphasis was on an holistic, qualitative study of accident causality, concentrating on depth over breadth and recognising that there is a montage of proximal and distal factors in construction accidents. Following a thorough literature review, seven focus groups were used to identify broad areas of interest and to help formulate the research instruments for the accident studies. The groups comprised 5-7 participants in the following categories: client team; senior managers; site managers; operatives (2 groups); safety professionals and a mixed group. 
100 accidents were then studied in detail, to collect further evidence. The accidents were a convenient sample with collaborating companies contacting the research team with initial information. Sampling was done on a quota basis to ensure a spread of accidents across construction build type and Government reporting accident categories. Initial reports were drawn up following site-based 'eye-witness' interviews and observations. These were evaluated by an independent expert review team and follow-up areas were identified. These leads were then investigated with further face to face or phone interviews. Finally an analysis of each accident was completed and incorporated within the overall project analysis which led to the published report (Figure 1).

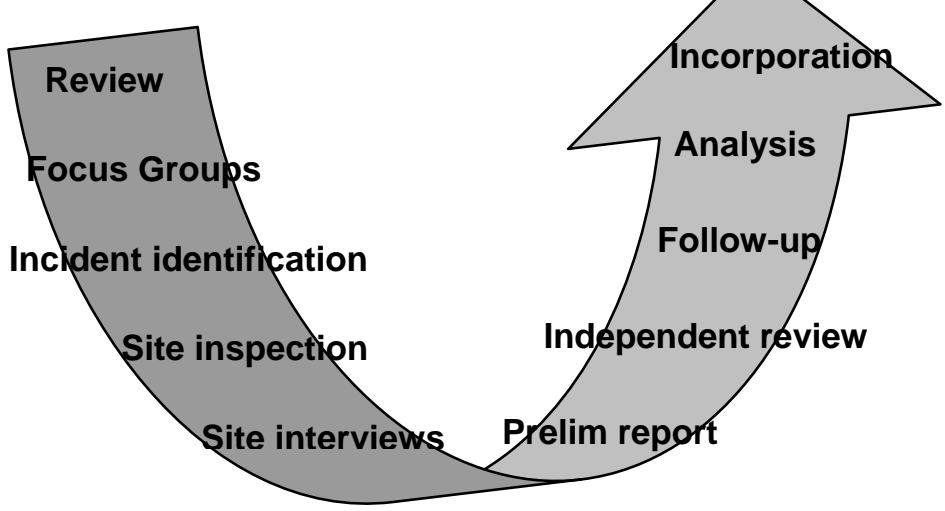

Figure 1 ConCA method (adapted from Hide et al, 2003)

The 100 accidents studied were used as a platform to explore the spectrum of causal factors which, by their nature, become less 'hard' the further they are away from the incident. The clear intention was not to lay blame, but rather to investigate possible causes and influences relating to each accident. The measure therefore, was not 'beyond reasonable doubt', but rather 'with reasonable confidence'.

This paper has been developed from a presentation at the international conference of the International Council for Research and Innovation in Building and Construction (cib W99), Sao Paulo, 2003 (Hide et al, 2003).

\section{Accident Causality - The Loughborough ConCA model}

The ConCA project has produced a causality model (Figure 2), that presents the factors influencing accidents on three planes, namely: immediate accident circumstances, shaping factors and originating influences. These planes can also be viewed in a similar way to Suraji et al's (2001) proximal and distal causes, in that they move from the more immediate and more easily demonstrable aspects, further along the causal chain where the links become more fuzzy and harder to firmly establish. As explained earlier, the concept of 'with reasonable confidence' was used to determine these more distal causes. 


\section{Originating Influences}

client requirements, economic climate, construction education

permanent works design, project management, construction processes safety culture, risk management

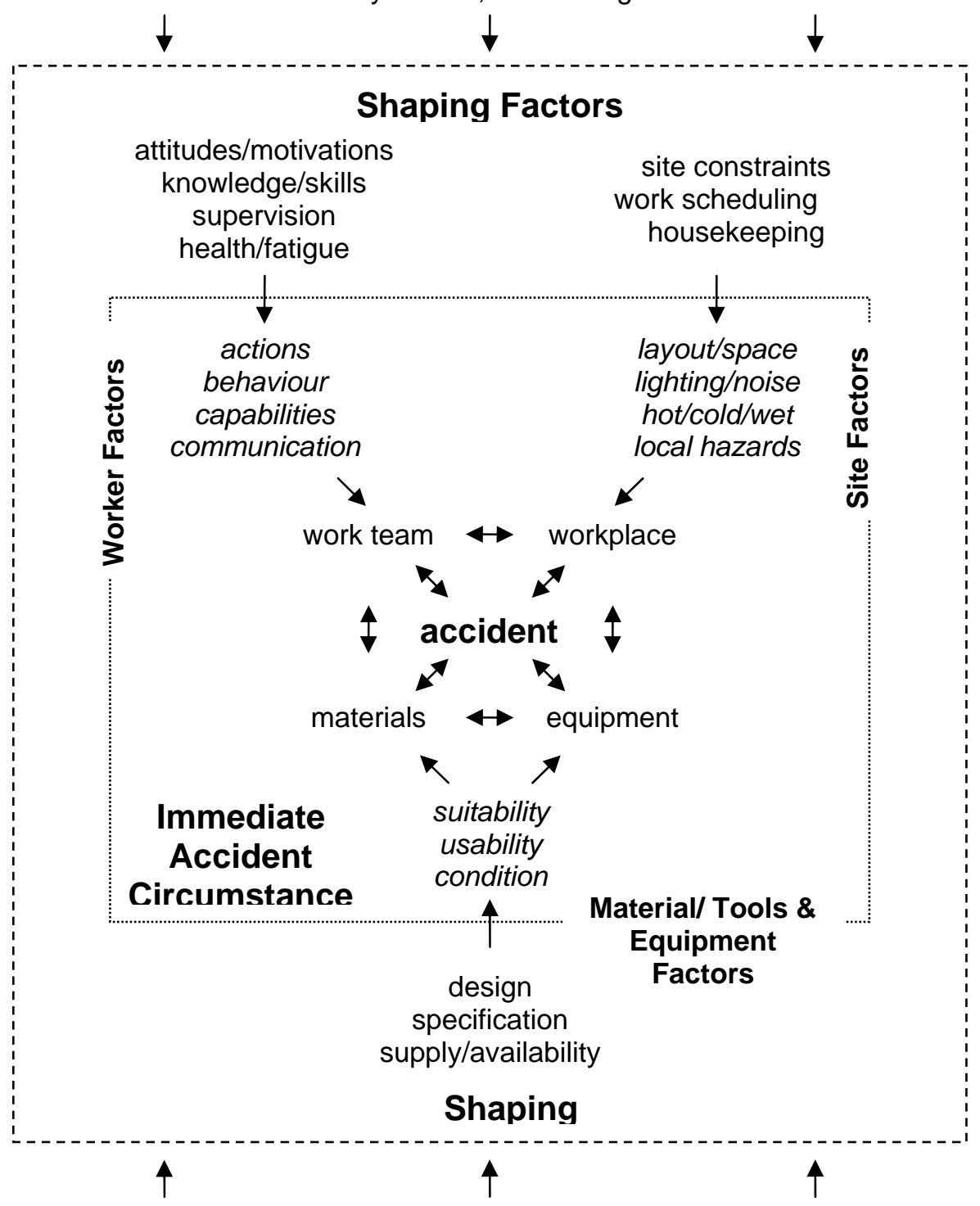

permanent works design, project management, construction processes safety culture, risk management

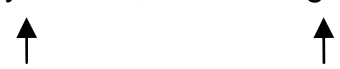

client requirements, economic climate, construction education

\section{Originating Influences}

Figure 2 Loughborough's ConCA construction accident causality model (adapted from Haslam et al, 2003) 


\section{Tools and equipment issues raised by the focus groups}

\subsection{Focus group method}

The aim of the seven focus groups was to consult stakeholders in the construction industry, exploring where failure occurs and why accidents still happen. A focus group is a style of group interview whereby the data obtained arises from the interaction and discussion generated from within the group (Morgan and Krueger, 1998). Groups are guided by a moderator, with a style that can be more or less directive, depending on the nature and purpose of the investigation. A degree of caution interpreting focus group findings is required. For example, groups may generate a level of conformity and acquiescence, suppressing individual views that might be felt in private. Alternatively, the researcher may direct discussion into an area unimportant to participants, or achieve this through data interpretation.

Nonetheless, focus groups are an established method for gaining insight into views surrounding a research question.

Table 1 describes the group categories and participants. Design professionals were not adequately represented in the focus group exercise and this is acknowledged as a limitation for this phase. However, designers were interviewed as part of the accident studies themselves. Each group considered where failure occurs and why accidents still happen, with the discussion covering project concept, design and procurement, work organisation \& management, task factors and individual factors. The groups were considering these issues from a generic perspective which was not based on knowledge or data from the subsequent accident studies.

Table 1 Focus Group categories and participants

\begin{tabular}{ll}
\hline Group & Participants \\
\hline Client team & $\begin{array}{l}\text { Client advisors, most with health and safety } \\
\text { responsibilities }{ }^{1}\end{array}$ \\
Senior managers & $\begin{array}{l}\text { Senior staff from general and specialist contractors } \\
\text { representing civil engineering, major building and } \\
\text { residential }\end{array}$ \\
Site managers & $\begin{array}{l}\text { Mix of general supervisory and managerial staff, some with } \\
\text { specific health \& safety responsibilities }\end{array}$ \\
Workers & $\begin{array}{l}\text { Two groups representing large and small sites from skilled, } \\
\text { semi-skilled and unskilled backgrounds } \\
\text { Industrial safety professionals and enforcement officers }\end{array}$ \\
Safety professionals & A mixed discipline group (trades and professionals) \\
\hline
\end{tabular}

\footnotetext{
${ }^{1}$ This group included Planning Supervisors who have a specific responsibility in UK legislation to coordinate health \& safety aspects, particularly through the design phase.
} 
The groups lasted about $1 \frac{1}{2}$ hours and audio recordings were made to permit subsequent transcription. An abridged transcription was made from each audiotape, recording the main points made as each participant spoke. This included a number of quotes where these were clear and salient points. To facilitate interpretation of the transcriptions, intermediate analyses were undertaken which involved summarisation of all text into short bullet point statements. These were a subjective interpretation by the researcher of the main points of what the speaker was saying. This enabled significant points to be extracted and permitted later comparison and categorisation of information according to the discussion area headings and sub-headings.

\subsection{Focus group findings on tools and equipment}

Although it was generally acknowledged that, where provided by the Principal Contractor, tools were often good and new to each site, it was indicated, that their selection was too cost motivated and that they were not always freely available. Equipment was reported as not always being of a good quality and that there were problems with the selection of the correct capacity tooling and providing adequate maintenance (directed in particular to lifting equipment). There were some concerns about the unknown quality of tools and equipment that was used by sub-contractors and of the use of multi-functional equipment, where tools are adapted for various uses other than that for which they were originally intended. One example, relevant to sub-contractor tool-use, was that, to compensate for unknown site circumstances, they are known to bring their largest capacity equipment to site, and proceed with using this although the equipment may in fact be too large for the task.

Availability and use of personal protective equipment (PPE) was reported to vary widely. The impression gained was that for larger companies there were plentiful supplies, but for smaller companies availability was limited and in some cases operatives were expected to provide their own PPE. It was acknowledged that nonuse of correct PPE does occur and, although this is more likely to happen at the weekend, use was seen as an individual's responsibility. It was indicated that those advocating the use of PPE do not adequately appreciate the practicalities and potential negative influence upon performance from its wear. For example, loss of mobility; helmets that impede vision and fall off unless secured by ear muffs; and goggles that steam up frequently interrupting work in order to clean them. 


\section{Tools and equipment issues raised by the accident studies}

\subsection{Accident study method and sample description}

The study method for the 100 accidents can be summarised as follows:

1. Obtain details of the incident and evaluate against sample frame ${ }^{2}$

2. Visit site and interview involved persons

3. Interview supervisors, managers, $\mathrm{H} \& \mathrm{~S}$ staff (as appropriate)

4. Draft initial study report

5. Review report by independent expert panels to identify potential follow-up

6. Follow-up studies (generally off-site)

7. Complete accident study report

One of the limitations of the study was that HSE (the UK Government health \& safety enforcer who was funding the project) stipulated that, for legal reasons, none of the accident studies should involve incidents that were being, or were likely to be investigated by the HSE. This meant that the study's accident outcomes were fairly minor in nature. It was therefore necessary to do an additional exercise to establish the likelihood that these accidents could have resulted in more severe consequences. In this way, almost a third of the incidents were judged to have had the potential to have caused a fatality and more than a half could have been classified as major events under the UK legislation RIDDOR ${ }^{3}$. This aspect is covered later in the paper and in detail in the HSE report (Haslam et al, 2003).

Table 2 provides a breakdown of the accidents studied by construction sector. It can be seen that civil engineering was over-represented, while the residential sector was under-represented against the original targets. Nevertheless, the table shows that the accidents occurred across the range of industry sectors.

Table 2 Distribution of the accidents studied $(\mathbf{n}=100)$

\begin{tabular}{lcccc}
\hline & $\begin{array}{c}\text { Engineering } \\
\text { construction }\end{array}$ & $\begin{array}{c}\text { Civil } \\
\text { engineering }\end{array}$ & $\begin{array}{c}\text { Major } \\
\text { building }\end{array}$ & Residential \\
\hline Target & 5 & 15 & 45 & 35 \\
Result & 4 & 25 & 49 & 22 \\
\hline
\end{tabular}

There was wide variation in the details of participating sites, ranging from short contract work to major building projects, being undertaken over a number of years. All but 16 of the sites were brownfield ( 4 unknown/missing data). Sites varied considerably in size, accommodating between 7-2500 personnel and with build schedules varying between 1 week to more than 10 years. From the 100 accidents, 71

\footnotetext{
${ }^{2}$ A sample frame was developed from the focus group and other expert input and knowledge such as the categories of accidents from existing accident statistics - these were used to draw up a matrix of project and accident characteristics. The ConCA project was seeking a spread of characteristics across this sample frame. This is explained in more detail in the HSE report (Haslam et al, 2003).

${ }^{3}$ RIDDOR - UK legislation - Reporting of Injuries, Diseases and Dangerous Occurrences Regulations (http://www.hse.gov.uk/pubns/hse31.pdf). Major injuries would include fractures, amputation, loss of sight, unconsciousness and acute illness requiring medical treatment.
} 
projects were reported to be running to time, 1 was ahead and 18 were behind schedule (10 unknown/missing data). Four of the sites were undertaking concurrent phases of their work, whereas 11 were in the 'start' phase, 58 in the 'middle' phase, 9 between 'middle' and 'end' phases, 7 in the 'end' phase and 2 in the 'after' phase (9 unknown/missing data). 4 projects included refurbishment activities. Many of the main UK principal contractors were represented.

The contract types were as follows:

- $\quad$ design and build / contractor led - including residential developers $(n=31)$

- integrated eg partnering / $\mathrm{PFI}^{4} /$ alliancing $(\mathrm{n}=24)$

- lump sum / fixed price / design then build $(\mathrm{n}=14)$

- construction management $(\mathrm{n}=13)$

- other contract types $(n=4)$

- unknown i.e. not identified in the accident study $(\mathrm{n}=14)$

\subsection{Accident circumstances}

Based on the accident book entries, in the opinion of the researchers, twelve of the 100 accidents should actually have been reported to the authorities under UK regulations. Of these, three were dangerous occurrences, eight resulted in absences of over 3 days and one was a major accident. The accidents were grouped according to conventional HSE categories (

\footnotetext{
${ }^{4}$ PFI - Private Finance Initiative - a collaborative approach used in the UK to obtain private finance for major projects that would otherwise have been funded by the Government.
} 
Table 3) (revised to combine slips, trips and all falls data together) with an additional category for 'injuries directly involving materials, tools or equipment' as this was found to be an important category that is not currently included by the authorities. 12 of the accidents were included in this category. In addition a further 5 were categorised as 'contact with/by moving machinery' and 5 as 'trapped by'. Both of these categories cover aspects addressed by this paper. 
Table 3 Distribution of accident types $(n=100)$

\begin{tabular}{|c|c|c|}
\hline Category & $\begin{array}{l}\text { Accidents number } \\
\text { reported }\end{array}$ & Total \\
\hline Slips, trips and falls (all levels) & $\begin{array}{l}16,17,23,36,37,46, \\
47,51,53,54,55,58, \\
62,64,73,75,77,81, \\
86,88,100\end{array}$ & 21 \\
\hline Injured while handling, lifting or carrying & $\begin{array}{l}5,14,15,28,29,31,33 \\
34,38,39,48,50,56 \\
57,76,83,84\end{array}$ & 17 \\
\hline Struck by moving (+ flying / falling) object & $\begin{array}{l}1,4,9,19,24,32,35 \\
43,44,61,63,68,69 \\
78,89,93,96,97\end{array}$ & 18 \\
\hline $\begin{array}{l}\text { Injuries directly involving materials, tools or } \\
\text { equipment }\end{array}$ & $\begin{array}{l}7,26,30,49,59,74,80 \\
87,92,95,98,99\end{array}$ & 12 \\
\hline Strike against something fixed or stationary & $\begin{array}{l}6,18,21,22,25,27,82 \\
91\end{array}$ & 8 \\
\hline Dangerous occurrences & $3,10,11,20$ & 4 \\
\hline Contact with/by moving machinery & $2,12,13,42,85$ & 5 \\
\hline Trapped by something collapsing or overturning & $60,65,70,72,90$ & 5 \\
\hline Contact with electricity or electrical discharge & 52,71 & 2 \\
\hline Other accident events types & $\begin{array}{l}8,40,41,45,66,67,79 \\
94\end{array}$ & 8 \\
\hline
\end{tabular}

Following the studies, the pattern of involvement of tools, equipment, materials and site / structure, along with the nature of the task or activity being undertaken at the time of the accident were analysed (Table 4). This further analysis showed that 28 accidents involved plant or equipment and 17 involved tools. 
Table 4 Activities and involved items within the accident sample $(n=100)$

\begin{tabular}{|c|c|c|c|c|c|}
\hline & Tools & $\begin{array}{l}\text { Plant / } \\
\text { equipment }\end{array}$ & Materials & $\begin{array}{l}\text { Site / } \\
\text { structure }\end{array}$ & Total \\
\hline Setting-up & & $31,42,74$ & 34 & $16,67,73$ & 7 \\
\hline $\begin{array}{l}\text { Actual task } \\
\text { activity }\end{array}$ & $\begin{array}{l}2,3,7,13, \\
14,26,30, \\
39,49,59, \\
65,87,89, \\
97,99\end{array}$ & $\begin{array}{l}8,11,29 \\
38,60,71 \\
94,79\end{array}$ & $\begin{array}{l}5,9,10,15 \\
33,35,40 \\
43,45,48 \\
57,63,80 \\
84,95,96\end{array}$ & $\begin{array}{l}20,24,27, \\
28,52,55, \\
58,61,77, \\
78,91,92, \\
93\end{array}$ & 52 \\
\hline $\begin{array}{l}\text { Clear-up / } \\
\text { maintenance }\end{array}$ & 98 & $\begin{array}{l}4,12,21 \\
32,46,56\end{array}$ & $\begin{array}{l}54,66,70, \\
83\end{array}$ & 82 & 12 \\
\hline $\begin{array}{l}\text { Movement / } \\
\text { transit }^{5}\end{array}$ & 50 & $\begin{array}{l}6,17,19, \\
22,36,37, \\
41,51,62, \\
85,90\end{array}$ & $1,25,44$ & $\begin{array}{l}18,23,47, \\
53,64,68, \\
69,72,75, \\
76,81,86, \\
88,100\end{array}$ & 29 \\
\hline Total & 17 & 28 & 24 & 31 & 100 \\
\hline
\end{tabular}

\subsection{Accident consequences}

As mentioned earlier, the limitations on the accident sample meant that most of the accidents studied had outcomes that were not reportable under the UK regulations $\left(\mathrm{RIDDOR}^{6}\right)$. To consider the significance of the research findings an exercise was completed to propose potential outcomes (Figure 3). These were established as 'likely' and 'possible' based on the RIDDOR classification. This rationale relied on an evaluation of the incident information and evaluation of alternative outcomes if the injured person had been in a slightly different location or if a different part of the body had been involved. Likely outcomes would require only a minor change in circumstances; possible outcomes would require a number of circumstances to change for them to occur. Some of the 'major' incidents may have led to permanent disability and hence loss of the individual to the industry. With a modest change in circumstances, it is likely that almost three-quarters of the accidents could have resulted in absences of more than three days and almost a quarter could easily have been major incidents. It is also likely that between 2 and 6 accidents could have resulted in fatalities. With a greater change in circumstances, the almost a third of the accidents could have resulted in fatalities and more than half would have been classified as major.

\footnotetext{
${ }^{5}$ Movement/transit here only includes on-site aspects. Travel to and from the place of work was not included in this study as it is not included in UK work-related legislation or statistics.

${ }^{6}$ RIDDOR - UK legislation - Reporting of Injuries, Diseases and Dangerous Occurrences Regulations (http://www.hse.gov.uk/pubns/hse31.pdf)
} 


\section{Likely outcomes}

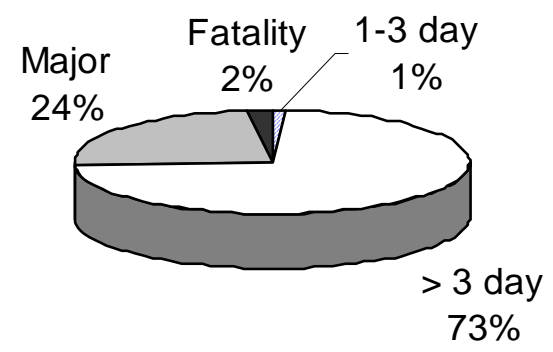

Possible outcomes

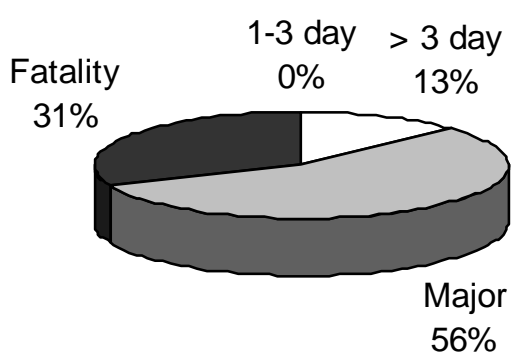

Figure 3 Likely and possible accident outcomes

\subsection{Analysis of causes}

Following the completion of the 100 accident study reports, further analysis was performed by the research team, combining construction and ergonomics expertise, based on their judgement of 'reasonable confidence' that a factor was causal in an accident. It should be borne in mind that was easier to be confident concerning the involvement of more immediate factors, eg worker actions or site hazards, than wider influences, such as safety culture. This is because the action of the immediate factors was direct and more obvious, while the involvement of other influences was more subtle. A summary of the findings from this further analysis is presented in Table 5 with 56 accidents now being found to be linked to tools and equipment. 
Table $5 \quad$ Summary of accident causes

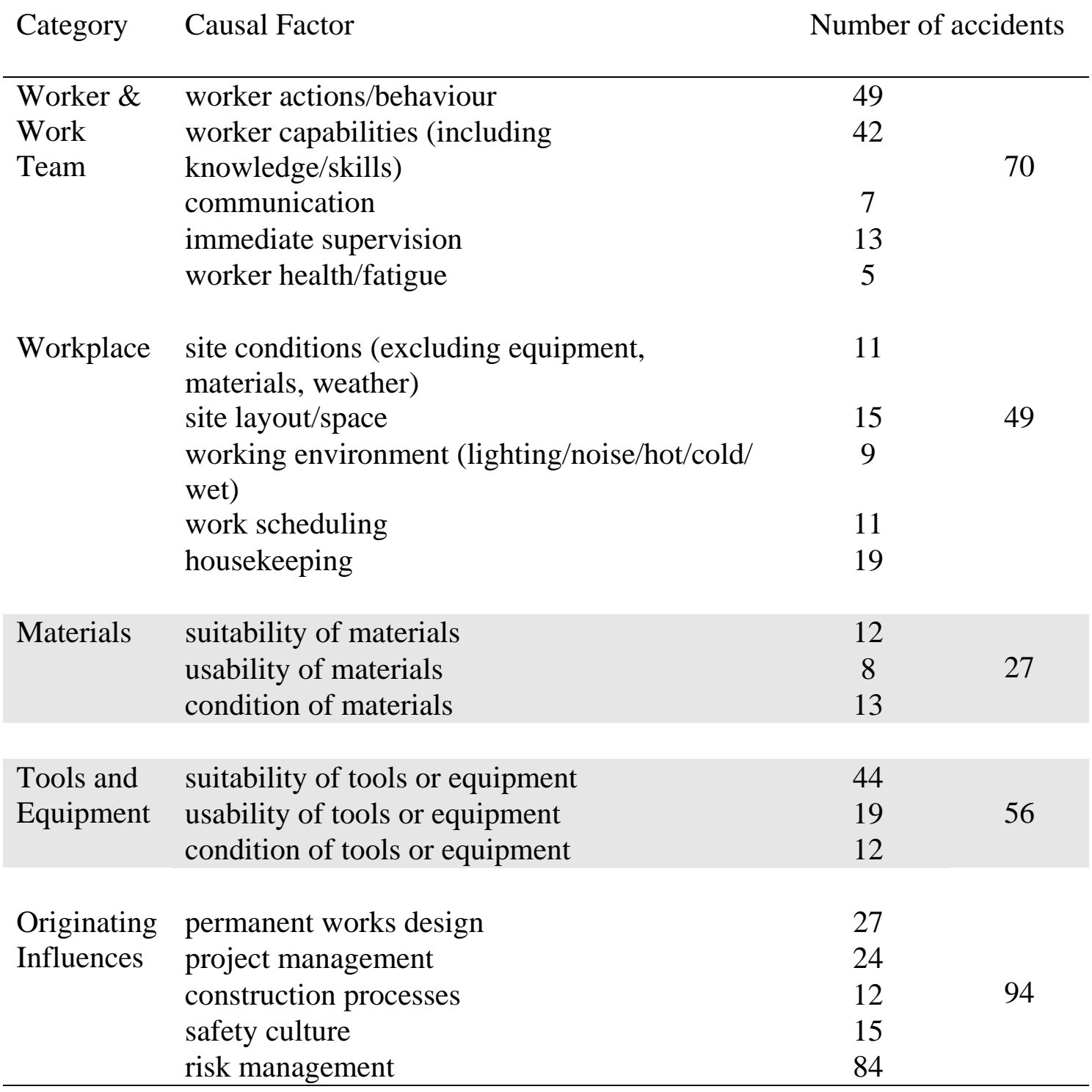

\subsection{Tools issues from the accident studies}

An assortment of tools featured in the accident studies, ranging from simple hand tools through to more sophisticated or powered tooling. Shortcomings in function or performance were reported by interviewees, with further problems with tool design observed by the researchers. Typical failings included poor grip characteristics, undesirable pressure at skin contact points and, for powered tools, frequent use of finger trigger operation. Some tools also appeared heavy, given the situations in which they were being used. For example, the petrol-powered circular saw and torque multipliers used in two of the accidents each weighed $11.5 \mathrm{~kg}$ and $8.9 \mathrm{~kg}$, heavy loads when used in awkward postures. It was observed that attempts to reduce problems with tools had been made by users through the addition of padding or tape on handles. Bladed tools required frequent unprotected handling of the cutting edge to change blades or to remove obstructions. One accident involved an electrocution 
due to deficiencies with the operation of a CAT scanner which failed to identify buried services. Time saving seemed to be an issue in tool use for other accidents.

A kerb lifter is available, but by the time you get it it's easier to use two people at each end...?

..The saw was quite a heavy and bulky tool for cutting the pipes, but a handsaw would have taken forever ...

Interesting comments were made about criteria for tool purchasing. The selfemployed often provided their own tools, although it was also reported that selfpurchase was sometimes preferable anyway due to the poor quality and condition of equipment supplied on site. In describing factors affecting their purchase choice, most interviewees seemed to aim for a 'middle of the road' price and selection according to manufacturer.

\section{... Tools in the $£ 15-40^{8}$ price range are all pretty much the same ...}

Tool pricing was a concern for many, especially when the tools were vulnerable to theft, or had a short life-span. In one case the tool performance (non-rusting) was referred to as a purchasing criterion. Interviewees obtained their tools from a specialist supplier or through mail-order catalogues. Some interviewees had been trained in use and care of their tools, but rarely since their apprenticeship. Others felt that they had just picked it up as they went along or relied solely on suppliers' information. Instructions were sometimes considered unhelpful and left unread. Specific training in tool use was rare - with safe use often considered to be common sense.

\subsection{Equipment issues from the accident studies}

Equipment, including machinery or plant brought onto site, was identified as deficient in more than half of the accident studies and in all cases was directly involved in the adverse incident. Failures relating to equipment included problems resulting from inadequacies in dimensions for user anthropometry or with the user interface. These problems were further compounded by shortcomings in performance, maintenance and safety-related features. Inappropriate physical dimensions of some equipment resulted in user interaction, such as physical or visual access, being hampered. In one accident a jump was required to climb off a scissor lift. Inspection of the equipment revealed that there were no distinct handholds on this equipment to support the user in this action. The safety cage on top of the scissor lift offered the most convenient points to grasp (at $2.2 \mathrm{~m}$ from the ground), yet fixing bolts here were left exposed, compromising the only handhold available.

We are taught to come down the scissor lift steps backwards, but the last step is about $2 \mathrm{ft}$ from the ground, so you have to jump the last bit ...

\footnotetext{
${ }^{7}$ These quotes have been taken from interviews of eye-witnesses to the incidents.

${ }^{8} \sim 25-67$ Euro
} 
A related problem occurred in connection with the length of ladder attached to the side of a rail wagon (Figure 4) which was being used to haul excavation spoil from a rail construction project. Elsewhere, use of split or cut down ladders was reported.

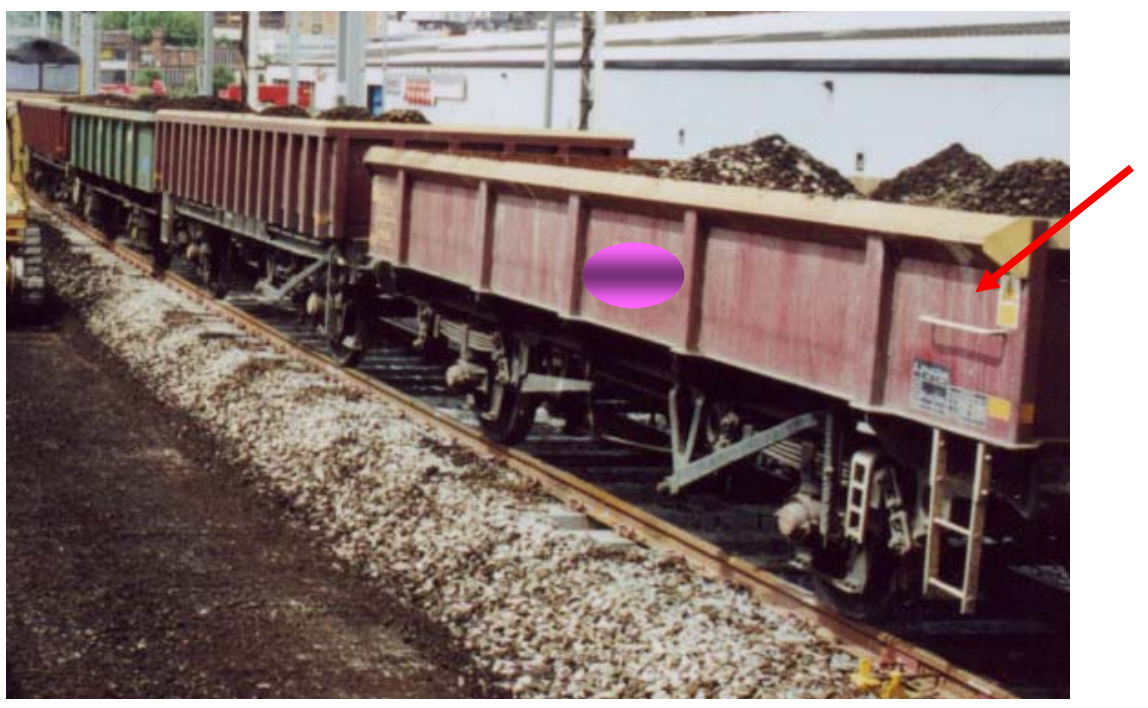

Whilst climbing ladder to view rail wagon contents, IP injured hand on top of wagon which had been damaged by a excavator loading spoil material into the wagon

\section{Figure 4 Inadequate ladder access to rail wagon}

In a similar context, problems were identified with the use of scaffold towers. In some instances difficulties had been experienced in achieving a desirable scaffold and handrail height for the work requirements, given the fixed height scaffold components available. Another example, commented upon spontaneously by interviewees in a number of accident studies, concerned the small size of access opening between different scaffolding levels. This access space was frequently too small for larger individuals, or those that might be carrying items about their person.

Problems had also arisen with operations involving manual movement of loads. In one case, load instability existed due to free movement of fuel within a fuel bowser. This situation was exacerbated by the design of the adjustable 'jockey' wheel at the front on the bowser (Figure 5). The fuel moved and caused the bowser to topple - the locking mechanism on the jockey wheel did not prevent the instability.

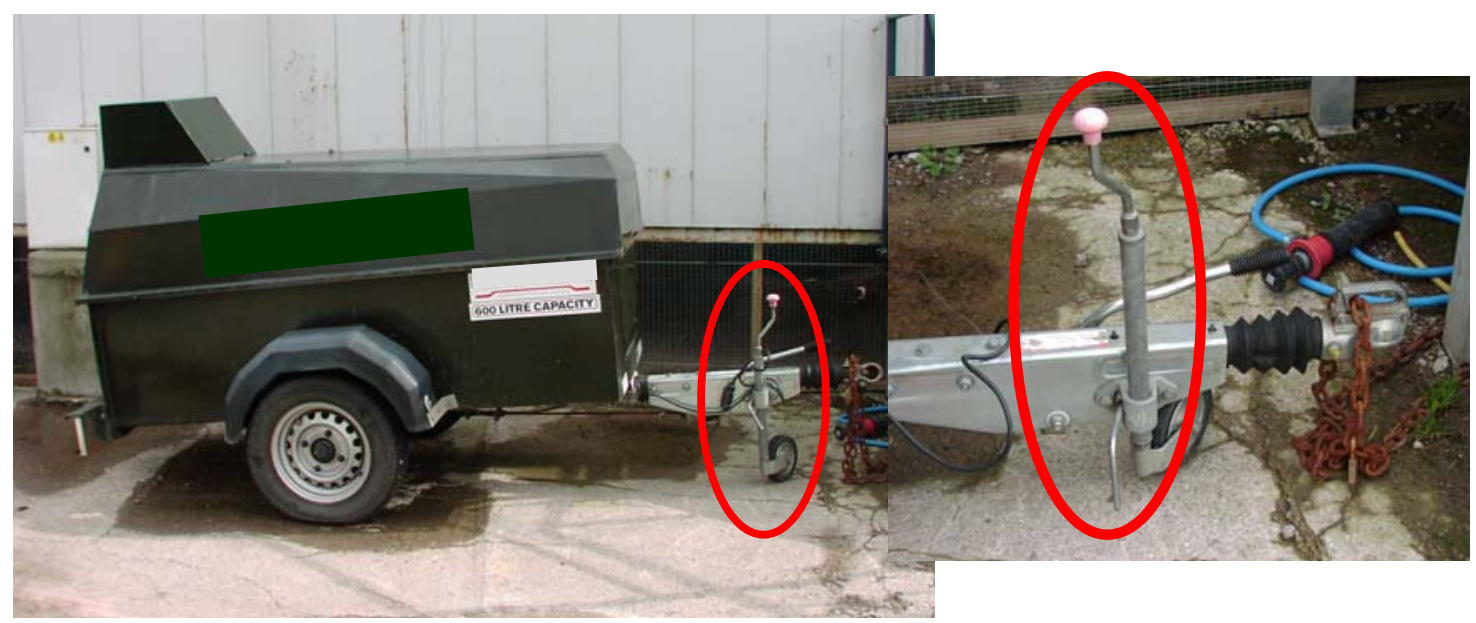

Figure 5 'Jockey wheel' failure on fuel bowser 
The design did not 'fail-safe' and had not utilised good practice from similar situations in other applications. For example, a very similar situation occurs in the caravan (small mobile homes) market in the UK, but in this case the design of the jockey wheel is much more sophisticated and the vehicle does not fall if the winder mechanism is incorrectly used.

In another accident, problems occurred manoeuvring a laden plasterboard trolley (Figure 6). The trolley had directional wheels at only one end (the other end having fixed forward facing wheels). While it was not known which end of the trolley was leading, difficulties were to be expected moving a full load with this particular trolley design.

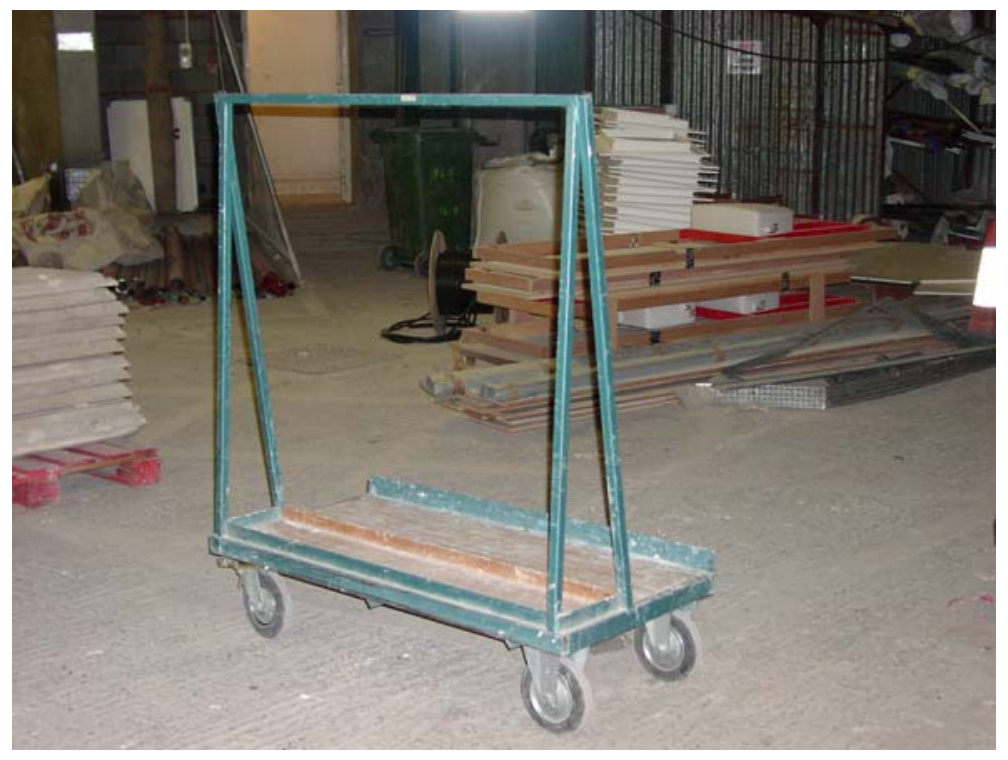

IP's hand was crushed against an adjacent scaffold handrail whilst removing plasterboard sheets from a fully loaded trolley.

\section{Figure $6 \quad$ Plasterboard trolley manual handling incident}

Equipment maintenance deficiencies featured in several accidents, especially with respect to steel parts (such as scaffold clips, concrete pipe clamps and extendable steel props). Weathering and concrete spillages on the equipment were reported as the main antagonists. Although 'regular cleaning and maintenance programmes' were in place, overcoming rust and similar problems added to the physical effort required to use equipment. Examples were found where the design of equipment gave little heed to its usability or how the user might detect and monitor different states. Figure 7 shows concrete placement pump and pipeline, where an operative injured his foot attempting to secure a pipe connection clip that had become excessively stiff due to concrete contamination. 


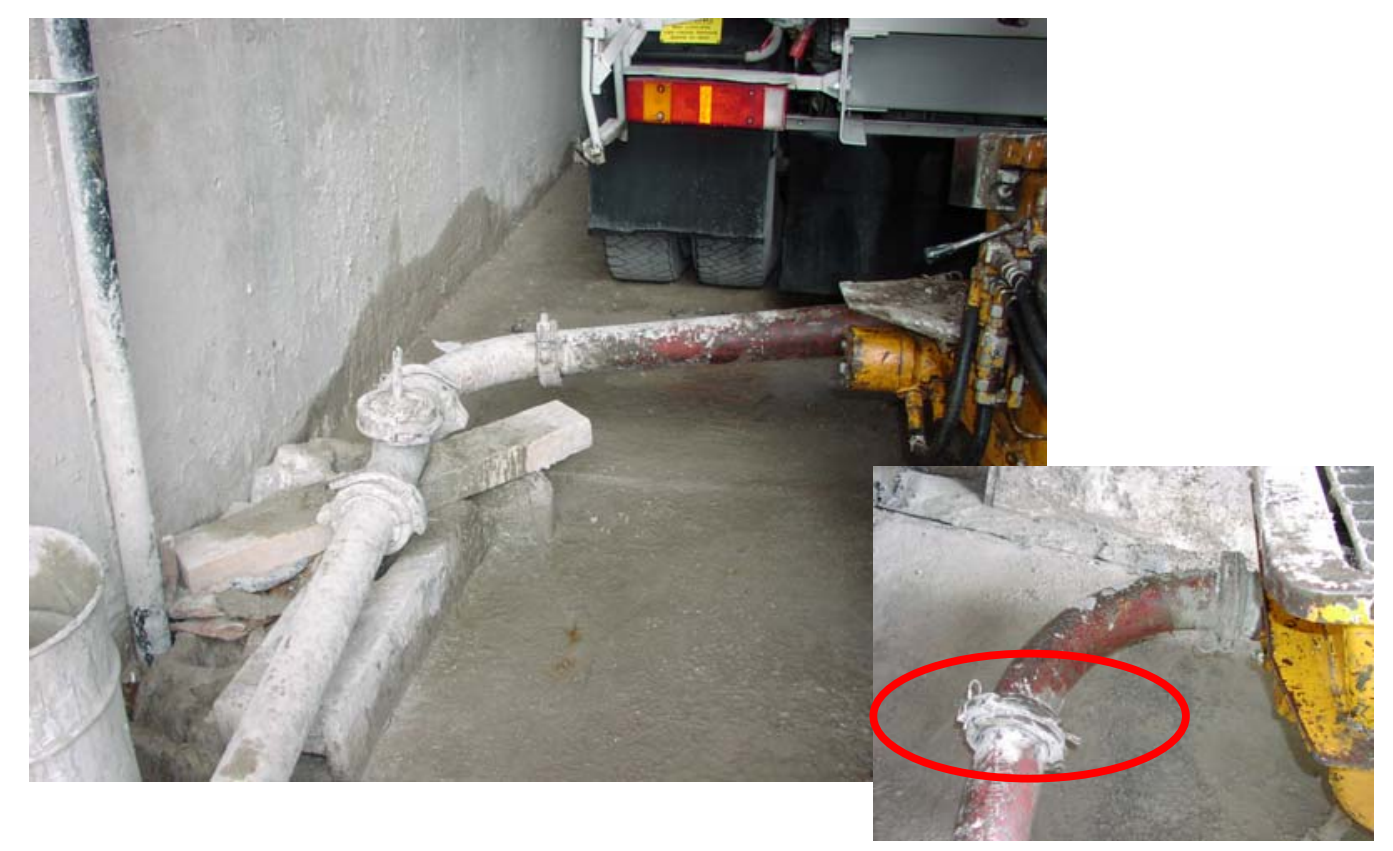

Figure 7 Concrete pump connection problems

Another accident involved an operative, whilst maintaining a crawler-mounted crane, falling from the running boards as the handle from the maintenance hatch gave way. Lack of feedback (eg visual, auditory or tactile information to the user) status of the equipment was a factor in several accidents. One accident involved a fire caused by an electrical fault on a pneumatic breaker which the supervisor considered had been caused by misuse of the equipment, but this damage had not been obvious to the operatives involved.

Usability issues were reported, for instance in the overturning of a delivery lorry where the interviewee described the wide range of lorry types he used in his work. There were common features however, such as the crane controls, but it was apparent that their design contravened user expectations (pushing the lever down raised the crane and vice versa). It was also reported that safety protection features built into the equipment did not anticipate this particular accident event.

Suitability of equipment was an issue in a number of accidents, where machines were being used for activities other then their primary purpose (eg excavators or forklifts used instead of cranes).

\subsection{Personal Protective Equipment (PPE) issues from the accident studies}

The use of a safety helmet, high visibility vest and safety boots was mandatory on all sites visited, with supplementary use of protective eyewear, gloves, harnesses and respiratory protective equipment expected depending on task type. Adverse comments were made about PPE in a large number of the accident studies. Criticisms related to poor fit and comfort; inappropriateness for actual task requirements; poor quality, care or condition; problems with availability and excessive cost. 
Comments concerning safety helmets focused on their frequent poor fit and comfort. Remarks were made about the lack of lining or padding, insecurity (due to lack of a chinstrap), poor ventilation (especially in summer) and being too small. Interviewees reported that helmets were regularly dislodged or fell off, induced headaches and interfered with work on looking up. In two of the accidents the injured persons' helmet fell off when they bent down, both then struck their head on something when they stood up.

Many interviewees accepted or were resigned to wearing a safety helmet, seeing them as a 'necessary evil' and in a number of the accidents helmets helped to reduce the extent of the injury. However, it was also said that they are not always needed, with some frustration at the lack of flexibility over when helmets needed to be worn. This seemed to suggest that, on some sites, there was an over-concentration on mandatory wearing of PPE (especially helmets) irrespective of the prevalent risks, whereas other risks were not always addressed. Figure 8 illustrates this point, with operatives rendering the external walls of a building wearing full PPE, including site helmets, although there is very little risk of anything falling on them. Whilst, in contrast, the very real danger of falling from a height of around 20 metres was not addressed in that no handrail is provided to their access scaffold. If they fell from this height their helmet would almost certainly fall off, and even if it did not, it would not prevent them from serious injury or, more likely, death.

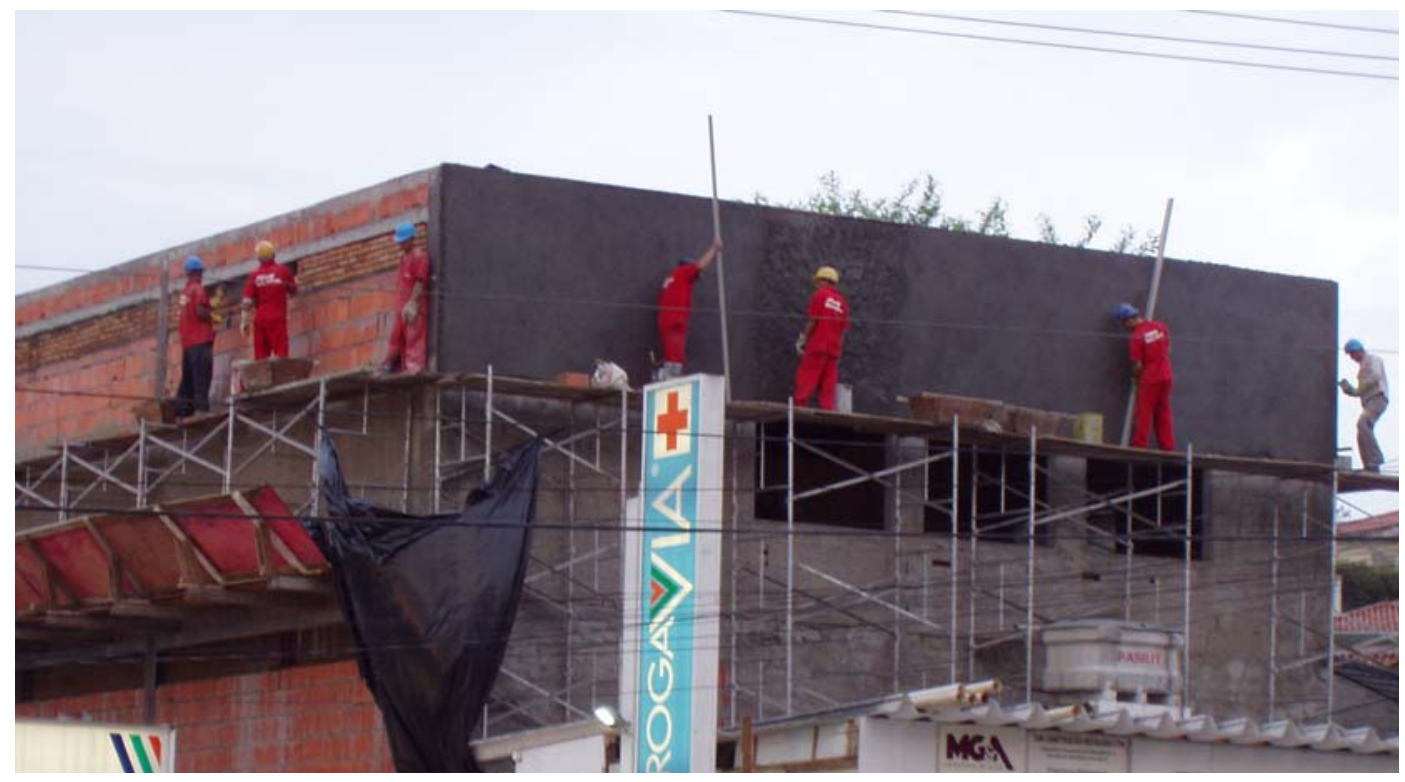

\section{Figure 8 Helmets worn but handrail missing}

In many of the accidents where the hands were at risk, the injured person was not wearing protective gloves. There were also complaints about the comfort and fit of gloves, with operatives not wearing them as they interfered with ability to operate tools and the speed with which they could undertake their work. Operatives reported inadequate supplies of gloves (necessitating use of worn out protection), inadequate durability and lack of a suitable size range. There were also reports that gloves were frequently mislaid with constant taking off and putting on. In some cases the gloves worn were not adequate to provide protection from the risk. 
Fall arrest harnesses were identified as issues in a small number of accident studies (only specified trades require use of this PPE), yet in these cases, there was a consensus of criticism about the equipment. These included complaints about comfort and fit (especially when used for longer than 30 minutes), concerns about restriction of mobility and inadequate supplies (leading to harness hoarding among site operatives). Interviewees were also worried that the 2-metre lanyard length was inadequate and that they would experience physical injury from the harness itself should they experience a fall. As with other PPE, it was acknowledged that harness use was necessary, but interviewees felt that they should be permitted greater discretion over when to wear fall arrest equipment.

With regard to other PPE, protective eye-wear was said to steam up and cause difficulties when performing certain tasks and under particular lighting conditions. There were problems with protective eye-wear for those needing to use 'prescription' glasses, although suitable prescription safety glasses are available. Respiratory protective equipment users mentioned problems with fatigue and being impeded when undertaking certain operations. There were also some complaints about highvisibility vests, concerning the obstruction they pose when trying to access tools from waist belts and a lack of fabric breathability, causing discomfort in hot weather.

Many interviewees reported having to buy their own protective footwear and in one case another reported purchasing his own protective eyewear. Interviewees reported receiving little instruction as to the maintenance of their PPE, although when asked about this respondents thought that care was 'down to the individual', or instruction unnecessary as they had used it for a long time.

Interviews with supervisor/managers indicated that PPE and its availability were viewed differently than by the workers themselves. These respondents were concerned about the lack of care given to PPE, with reports of finding new and expensive PPE treated badly, left lying around or improperly looked after. Ordering and choice of PPE was, in a number of instances, undertaken by 'Head Office', although in other cases supervisor/managers were involved. Only a few had tried ordering new styles, prompted by recommendation, observation of use by other construction teams, or through information provided in supply catalogues. One interviewee reported working with glove manufacturers to trial new products and another, in the case of a new short peaked hat, had tried it themselves to assess the product.

Whilst there were instances of operatives claiming that PPE impeded their work, there was no evidence in the studies to suggest that the enforced wearing of PPE caused the wearers to take more risk. This is contrary to the suggestions of Aranda \& Finch (2003) quoting the risk homeostasis theories of Wilde (1988) and Yates (1992). 


\section{Conclusions}

The ConCA project has shown that tools and equipment, including PPE, were an important causal factor in the 100 construction accidents studied. The number of accidents with causal links to tools and equipment increased as a closer study along the causal chain was completed (Accident book 12; initial site-based study 45; further analysis 56).

ConCA argues that a category should be added to the statutory reporting procedures to record the involvement of tools and equipment in accidents. In this way their contribution to accident causality can be properly evaluated. In the meantime, all involved in the construction process should look to improve communication and feedback loops with tools and equipment designers and suppliers. Companies should carefully evaluate tools chosen and ensure that lowest cost is not the main criteria for their selection. Managers and operatives alike should ensure that tools and equipment and well maintained and replaced frequently.

\section{References}

1 Abdelhamid, T.S., and Everett, J.G, (2000) Identifying Root Causes of Construction Accidents, Journal of Construction Engineering and Management, 126 (1), pp. 52-60.

2 Aranda, G. \& Finch, E., (2003) Using repertory grids to measure changes in risktaking behaviour, Journal of Construction Research, Vol. 4, No. 1, pp. 101-114.

3 Haslam, R.A., Hide, S.A., Gibb, A.G.F., Gyi, D.E., Atkinson, S., Pavitt, T.C., Duff, R. \& Suraji, A. Causal factors in construction accidents, Health and Safety Executive, HSE Report, RR 156, September 2003, 222 pp, ISBN 071762749 7, www.hse.gov.uk/research/rrpdf/rr156.pdf

4 Haslam, R.A., Hide, S.A., Gibb, A.G.F., Gyi, D.E., Pavitt, T., Atkinson, S. \& Duff, A.R., Contributing factors in construction accidents, Applied Ergonomics, Invited paper, special edition on ergonomics in building and construction, Vol 36, Issue 4, July 2005, pp. 401-416, ISSN 0003-6870

5 Hide, S., Gibb, A.G.F., Haslam, R.A., Gyi, D.E., Atkinson, S. \& Duff, R., (2003) Accident causality - the influence of tools and equipment, Proceedings of the International Conference of CIB Working Commission W99, Sao Paulo, Brasil, March, pp. 1-11.

5 Hide, S., Gibb, A.G.F., Haslam, R.A., Gyi, D.E., Hastings, S. \& Duff, R., (2002) ConCA - Preliminary results from a study of accident causality, Proceedings of the Triennial International Conference of CIB Working Commission W99, Hong Kong, May, Rowlinson, S. (ed), pp. 61-68, CIB Publication 274, ISBN 9627757047.

6 Hide, S., Hastings, S., Gyi, D.E., Haslam, R.A. \& Gibb, A.G.F., (2001) Using focus group data to inform development of an accident study method for the construction industry, Contemporary Ergonomics, Conference of the Ergonomics Society, Hanson, M. A. (ed), Taylor and Francis, London. 153-158, ISBN 0415 250730

7 Hide, S., Gibb, A.G.F., Hastings, S., Haslam, R., Gyi, D., Suraji, A. \& Duff, R., (2000) By accident or design? Causal factors in construction industry accidents, 
Proceedings of the International Conference of the European Construction Institute and the CIB Working Commission W99, London, June 2000, Designing for Safety \& Health, Gibb, A.G.F. (ed), pp 45-52, ECI, Loughborough, ISBN 1873844484

8 Hinze, J., (1996) The distraction theory of accident causation, Proceedings of the International Conference of CIB Working Commission W99, Lisbon, Alves Dias \& Coble (eds), AA Balkema, Rotterdam, Brookfield, pp. 375-384, ISBN 905410 8479.

9 Morgan D L and Krueger R A, 1998. The Focus Group Kit. Sage, Thousand Oaks, California.

10 Reason, J. (1990), Human Error, Cambridge University Press, 302 pp., ISBN 0521 314194.

11 Suraji, A., Duff, A.R. and Peckitt, S.J., 2001, Development of a causal model of construction accident causation Journal of Construction Engineering \& Management, American Society of Civil Engineers, July/August 2001, Vol. 127, No. 4.

12 Whittington, C., Livingstone, A. and Lucas, D.A., 1992, Research into Management, Organisational and Human Factors in the Construction Industry. HSE Contract Research Report 45/1992. HMSO: London.

13 Wilde, G., (1988) Risk homeostasis theory and traffic accidents: propositions, deductions and discussion of dissention in recent reactions, Ergonomics, Vol. 31, No. 4, pp. 441-468.

14 Yates, F., (1992) Risk taking behaviour, John Wiley \& Sons, Chichester, England. 